\title{
A Locally Invasive Giant Cell Tumor of the Skull Base: Case Report
}

\author{
J. T. Billingsley ${ }^{1}$ \\ R. M. Wiet $^{2}$ \\ G. J. Petruzzelli ${ }^{3}$ \\ ${ }^{1}$ Department of Neurosurgery, Rush University, Chicago, Illinois, \\ United States \\ 2 Department of Otolaryngology - Head and Neck Surgery, Rush \\ University, Chicago, Illinois, United States \\ ${ }^{3}$ Department of Otolaryngology, Rush University Medical Center, \\ Chicago, Illinois, United States
}

J Neurol Surg Rep 2014;75:e175-e179.
R. Byrne ${ }^{1}$

\author{
Abstract \\ Keywords \\ - giant cell tumors \\ - GCT \\ - epiphyses \\ - extremities \\ - temporal bone \\ - skull base tumor \\ - radiotherapy
}

\begin{abstract}
Address for correspondence Joshua Thomas Billingsley, MD, MS, Department of Neurosurgery, Rush University, 1725 W. Harrison St., Suite 855, Chicago, IL 60612, United States (e-mail: jtbill@hotmail.com).
\end{abstract}

Giant cell tumors (GCTs) are rare, usually affecting the epiphyses in long bones of the extremities. They seldom occur in the skull, where they preferentially affect the sphenoid and temporal bones. Considered to be benign, locally aggressive lesions, they may cause cranial nerve deficits by compression but infrequently invade the dura and parenchyma of the brain. Several case reports with follow-up describe gross total resection of skull base GCT to be curative. Anything short of total resection usually results in recurrence within 4 years. Radiation therapy, although controversial, is reserved for lesions that cannot be completely resected. Some argue, however, against the use of radiation because there are reported cases of malignant transformation. Here we describe the case of a large GCT that was invasive to the dura, temporal lobe, as well as the third division of the trigeminal nerve, and to date gross total resection has been curative of this lesion. The patient has not undergone radiation therapy.

\section{Introduction}

Giant cell tumors (GCTs) are rare lesions that develop in the epiphyses of long bones in the extremities. They are exceptional lesions when they occur in the skull, and then are usually found in the sphenoid or temporal bones. GCTs are considered benign lesions. Their adverse effects are usually the result of compression, often causing cranial nerve deficits relative to their position. It is uncommon for these lesions to invade dura or brain. However, even in these cases where GCTs appear to be more 'aggressive', gross total resection is curative. Several cases with substantial follow up have described gross total resection to be adequate for cure. Here we describe the case of a patient that presented with a large GCT that was invasive to the dura, temporal lobe, as well as the third division of the trigeminal nerve. To date, gross total resection has been curative. The patient has not undergone radiation therapy.

\section{Case Report}

A 44 year-old woman initially saw her primary care physician for right ear pain and fullness in April 2010. She was treated with antibiotics and steroids, but an effusion persisted. In May, she saw an audiologist who noted mild conductive hearing loss on the right, and, subsequently, a right tympanostomy tube was placed. After this, nearly a year passed and the patient began to notice significant hearing loss in her right ear. She was referred to a community otolaryngologist, and, on examination, a small mass was noted in the right external auditory meatus (-Fig. 1A). Computed tomography and magnetic resonance (MR) imaging of the brain and temporal received

September 10, 2014 accepted after revision April 19, 2014

published online

June 24, 2014
DOI http://dx.doi.org/ 10.1055/s-0034-1378153. ISSN 2193-6358.
Copyright (c) 2014 by Georg Thieme Verlag KG, Inc., Stuttgart · New York Tel: +1(212) 584-4662.
License terms

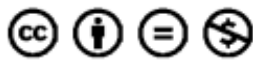




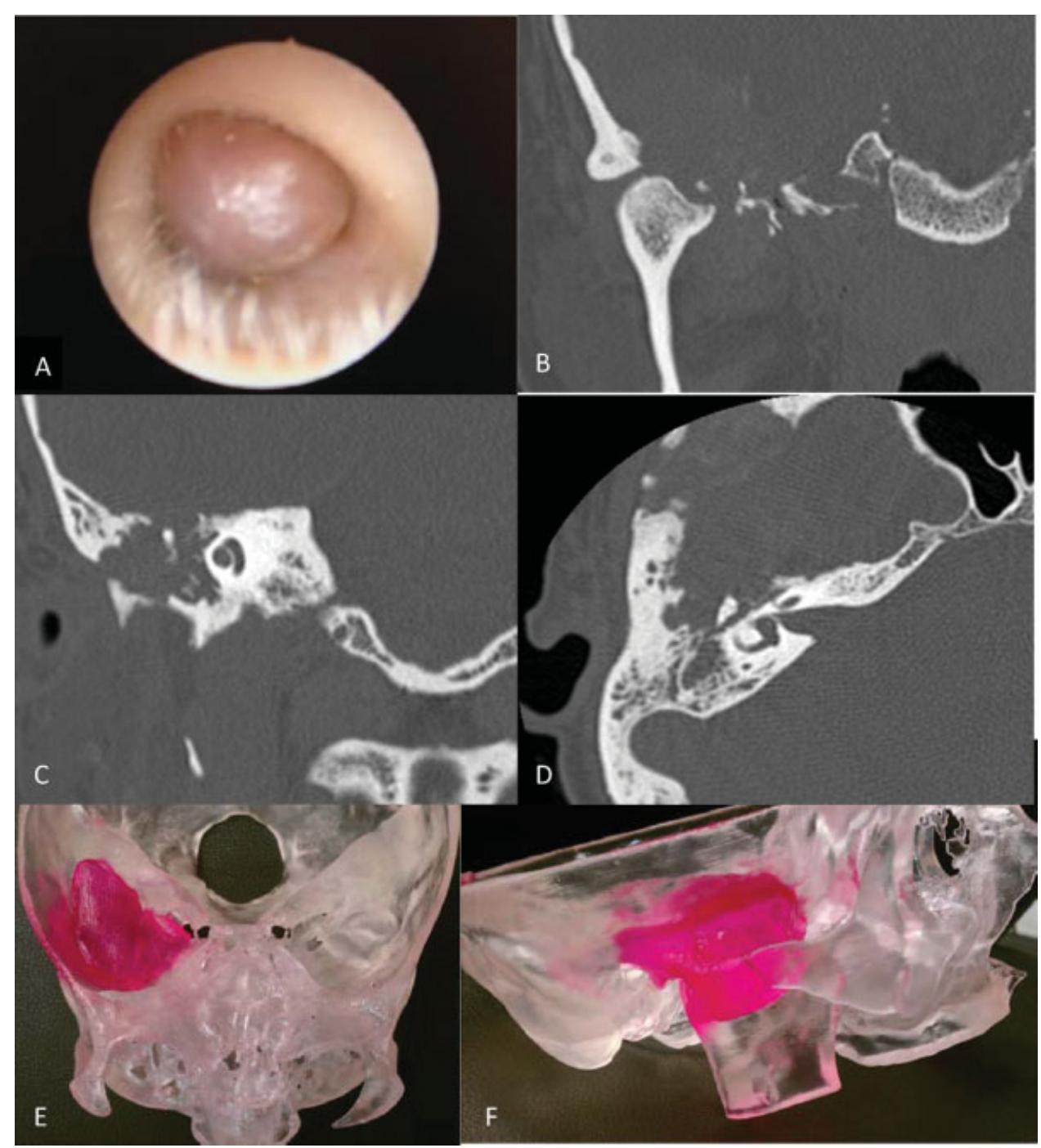

Fig. 1 (A) Photo of the right external auditory meatus taken during an otoscopic examination when the patient was initially seen in the Ear, Nose, and Throat clinic, early July 2011. (B, C) Coronal and (D) axial slices of computed tomography bone windows showing temporal and petrous bone prior to resection. (E) Anteroposterior Towne and (F) lateral view of tumor model.

bone were performed (-Fig. 1B-D), and she was then referred to both the ears, nose, and throat (ENT) and neurosurgery departments at our institution in early July 2011. The patient underwent biopsy of the lesion from the external auditory meatus (EAM) a few days later that revealed giant cell tumor. Surgical excision was scheduled involving both the ENT and neurosurgery departments.

\section{Examination}

At the time of surgery, the patient had no focal motor deficits, and her only sensory deficit was decreased hearing in the right ear. Audiology reports revealed moderate conductive hearing loss on the right with a speech reception threshold of $35 \mathrm{~dB}$ in the right ear and $25 \mathrm{~dB}$ in the left ear. Word recognition was $100 \%$ bilaterally when confronted with slightly lower than normal conversational speech. There was no pathologic adenopathy identified, but there was fullness and tenderness over the right temporomandibular joint. There was excursion and drift of the mandible to the left and a cross-bite deformity.

\section{Operation}

Initially, a tracheostomy was performed with the patient supine and, after securing a number 6 Shiley tracheostomy tube in place, the patient was positioned left lateral with the right side of the head facing upward and the vertex of the head slightly down. A right-sided postauricular infratemporal approach was made to the skull base. The skin flap, incised to the temporalis facia, was rotated forward. To facilitate this, the external auditory canal was transected and oversewn, and the facial nerve was identified and dissected from the parotid gland. The frontal branch had to be completely dissected and mobilized inferiorly with a cuff of the temporalis facia to gain adequate exposure to the zygoma and root. An osteotomy of the zygoma was made at the malar eminence anteriorly. Posteriorly, the zygoma was left intact, as a part of the specimen, because the root was heavily involved with tumor. The temporal muscle was incised below the superior temporal line and reflected posteriorly to gain exposure to the squama for a subtemporal craniectomy. 


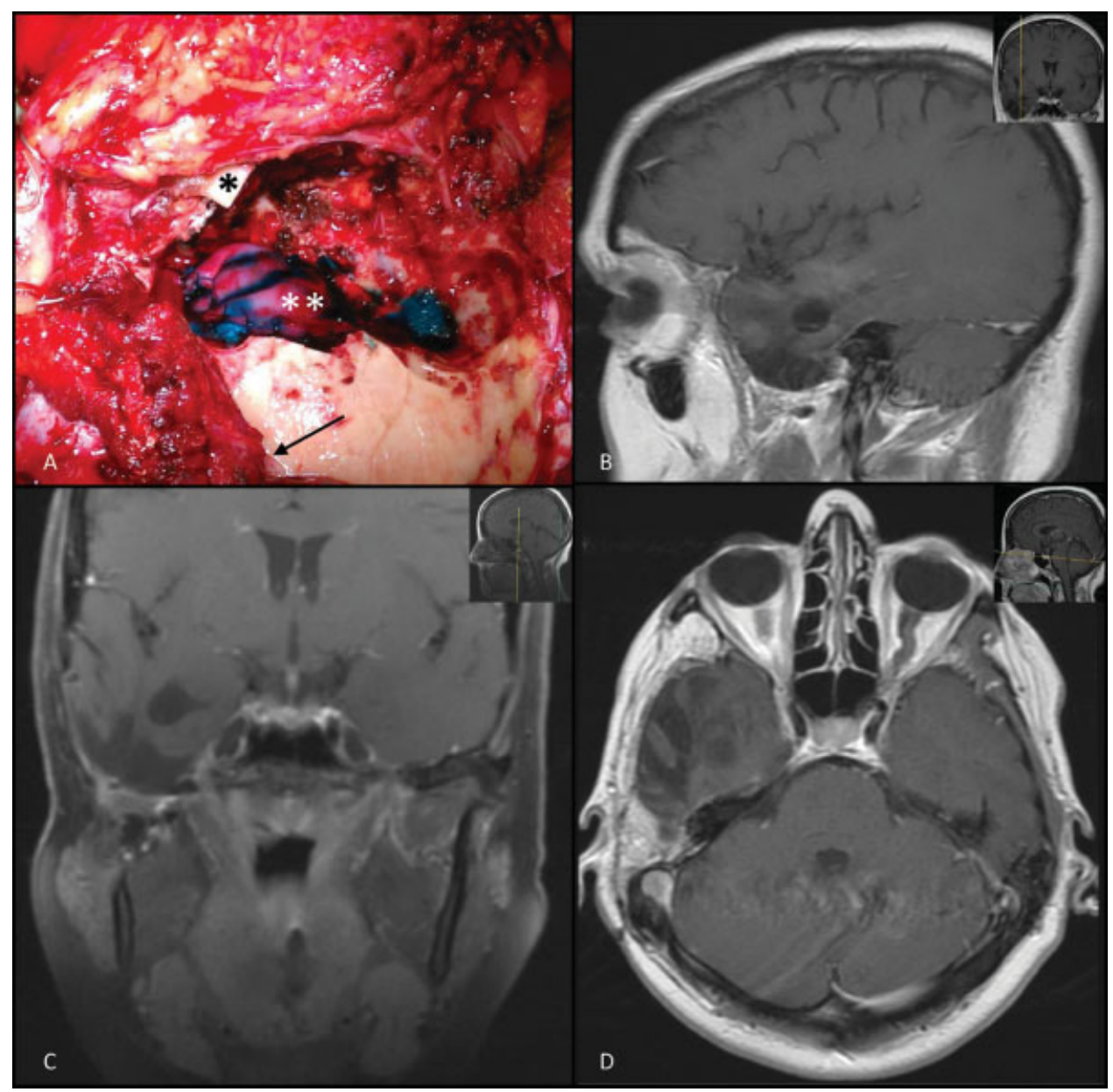

Fig. 2 (A) Intraoperative photo showing the resection cavity. A portion of the temporal lobe and dura were removed and repaired with a dural substitute and sealant. The temporal floor, zygoma, and portion of the upper mandibular ramus were invested with tumor and resected. Zygomatic arch (asterisk), temporal lobe (double asterisk), and duraplasty (arrow; superior temporal line). (B) Sagittal (C) coronal, and (D) axial views of 19-month follow-up magnetic resonance imaging showing no tumor recurrence and good reconstruction with a rectus free flap.

Next, a subtotal petrosectomy was performed to expose the intratemporal seventh nerve distal to the geniculate ganglion, identify and control the sigmoid sinus, and obtain negative bone margins at the zygomatic root. The roof of the glenoid fossa was also exposed.

At this stage, a subtemporal craniectomy was performed, and the floor of the middle fossa was resected as far medially as the foramen ovale. The tumor could be seen entering the dura, and a durotomy was made lateral to this point. Intradurally, the tumor was clearly invasive and adherent to the brain, so, microscopically, the lesion was resected down to normal-appearing white matter at all margins. The dura was resected medially to the lateral pterygoid plate. Grossly, the tumor involved the third division of the trigeminal nerve, which was sacrificed at the foramen ovale.

Finally, the roof of the glenoid fossa was mobilized and an osteotomy was made in the mandible at mid-ramus, resecting the condyle, the coronoid, and the temporomandibular joint. After dissecting and mobilizing the infratemporal portion of the tumor, the upper mandible, glenoid, a portion of the floor of the middle fossa, and the tumor were removed en bloc. The dura was repaired with a dural substitute and sealed with a polyethylene glycol-based sealant (-Fig. 2A).

\section{Postoperative Course}

The patient tolerated the procedure well and was taken sedated to the neurosurgical intensive care unit for monitoring. She was electively returned to the operating room the following day for reconstruction of the defect with a rectus abdominis free tissue transfer and split thickness skin graft. At 15-month follow-up, her MRI showed gross total tumor resection with no evidence of recurrence (-Fig. 2B-D). She had mild dullness to sensation on the right side of her face, her right seventh nerve palsy had completely resolved, and she had conductive hearing loss in her right ear due to the EAM being sewn over. She is currently considering options for rehabilitating her conductive hearing loss. She did not receive adjuvant radiation therapy.

\section{Pathology}

Histologic analysis of the biopsy specimen revealed an infiltrative lesion beneath the epidermis ( - Fig. 3A). The lesion consisted of predominantly mononuclear cells with abundant eosinophilic cytoplasm. Admixed among the mononuclear cells were many multinucleated giant cells and hemosiderin pigment consistent with giant cell tumor. Throughout the lesion were many hemosiderin-laden macrophages and hemorrhage. 


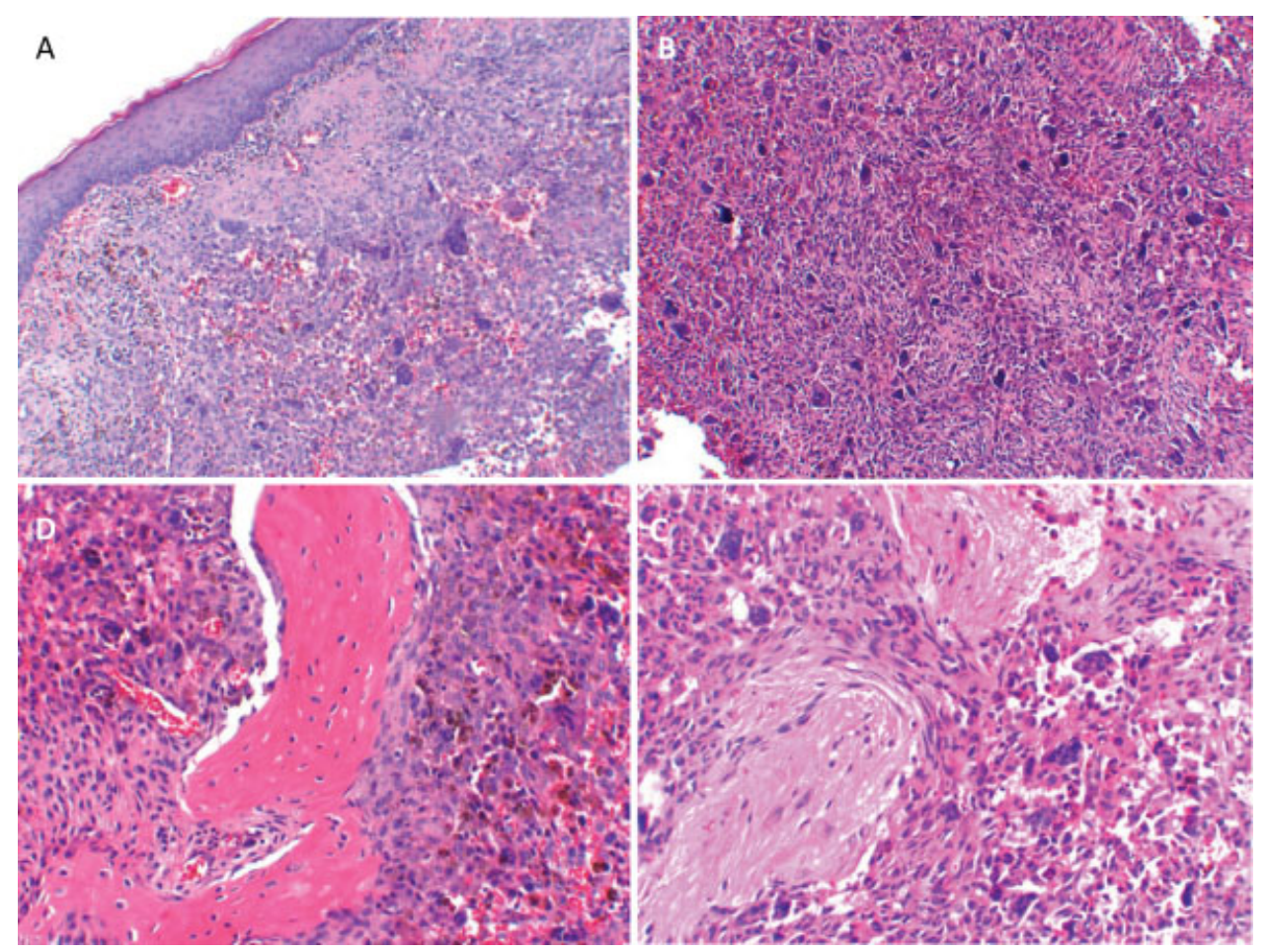

Fig. 3 (A) Infiltrative giant cell tumor (GCT) beneath the epidermis showing characteristic mononuclear cells, hemosiderin pigment, and multinucleated giant cells. Heavy infiltration of GCT in (B, C) brain and (D) bone.

Analysis of the resected lesion showed giant cell tumor within the right middle ear, eustachian tube, invading the bone and dura of the middle fossa as well as the adjacent

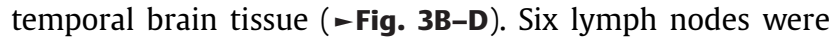
dissected from the right neck near the infratemporal region of the tumor, and these were negative for malignancy.

The overall histologic appearance did not suggest an aggressive lesion. It had characteristics of a typical GCT and therefore appeared biologically benign. No abnormal mitoses were identified, and the mitotic count was low. Features that may suggest a more aggressive lesion, such as vascular invasion, were not identified, and there were no sarcomatous changes.

\section{Discussion}

GCTs of the skull are very rare lesions. Bertoni et al reviewed 546 Mayo Clinic cases of GCT and identified 4 cases involving bones of the skull base. ${ }^{1}$ A further review of 1500 Mayo consultation cases revealed just 11 more cases of skull GCT. These lesions preferentially arise from the sphenoid and/or temporal bones, ${ }^{2,3}$ which may be due to the fact that the skull base and portions of the temporal bone form by endochondral ossification, rather than intramembranous ossification like other bones of the skull. This is the same process by which bone forms in the epiphyses of long bones where GCTs are primarily found. ${ }^{4}$ The multinucleated giant cell of the GCT closely resembles the osteoclast that is prevalent in these ossification centers of long bones. ${ }^{5,6}$

Defining cellular and molecular characteristics of more aggressive GCTs have been difficult to elucidate. Studies of GCT in long bones has shown that a higher count of mitotic figures per given field has not been consistent in identifying more aggressive lesions. In fact, Sanerkin's study of 90 GCTs revealed lesions possessing as many as 6 to 10 mitoses $/ \mathrm{mm}^{2}$ were not necessarily aggressive; nor did they recur more often. ${ }^{7}$ However, all of the tumors possessing $\geq 10$ mitoses/ $\mathrm{mm}^{2}$ were aggressive, defined by their invasiveness and recurrence. Malignant potential also could not be consistently determined by higher mitotic rate, abnormal mitoses, or vascular invasion. In general, malignant GCTs had higher mitotic counts, but one of the defining properties of lesions with malignant metastases was sarcomatous degeneration. ${ }^{7-9}$ Therefore, with the exception of sarcomatous change, the histologic features of a GCT often do not seem to correlate with the lesion's local aggressive nature or metastatic potential. The tumor discussed in this report was locally destructive and invaded bone, dura, and brain, but its histologic appearance was that of a standard benign GCT. Recurrence of giant cell tumors in the skull, and in long bones, seems to be directly related to the extent of resection. $3,7,10$

It is not clear what molecular properties of the GCT permit it to be locally invasive or metastatic. Some lesions barely affect adjacent tissue, whereas others invade and dissolve local tissue and bone. Ueda et al showed that giant cells can express matrix metalloproteinase-9 (MMP-9), which can dissolve type IV collagen. ${ }^{11}$ This collagen is a major structural component in the basement membranes of blood vessels. MMP-9 also has the capacity to degrade type I and V collagen, a major component of bone. Although this may allow the tumor to be locally aggressive, vascular invasion and tissue destruction alone is not sufficient for metastasis of GCT. Only $\sim 2 \%$ of these lesions are metastatic. 
The large rare GCT presented here was invasive to dura, brain, and the fifth cranial nerve and was treated with radical resection. We are aware of only two existing reports of invasive adult GCT. ${ }^{12,13}$ One of these lesions was invasive to adjacent dura only and the other to dura and brain. Because portions of each of these lesions were unresectable, both were treated with partial resection and radiotherapy. Radiotherapy is recommended for tumors such as these that cannot be completely resected, for patients who cannot undergo surgery because of comorbid factors, or for patients with progressing or multiple recurrences after surgical excision. Some advocate treating patients that they feel are at especially high risk of recurrence. Nonetheless, treating GCTs with radiation is still somewhat controversial. Earlier studies reported sarcomatous malignant degeneration in some tumors that were irradiated. $3,7,14$ It seems, however, that sarcomatous transformation occurs with similar frequency in tumors that have been irradiated, as well as those treated with surgery alone. $^{15,16}$ More recent reports with follow-up ranging from 2 to 34 years revealed no cases of malignant transformation when using 35 Gy in 15 doses. ${ }^{17}$ Radiotherapy should be used as an adjunct. When used as a single modality, recurrence rates of 60 to $70 \%$ have been reported. ${ }^{18}$ The patient in this study is $>2$ years out from surgery with no sign of recurrence. We believed we could achieve a gross total resection based on a thorough analysis of the lesion size, location, and invasiveness. Time will tell if resection alone is an adequate and durable treatment for this lesion.

\section{References}

1 Bertoni F, Unni KK, Beabout JW, Ebersold MJ. Giant cell tumor of the skull. Cancer 1992;70(5):1124-1132

2 Wolfe JT III, Scheithauer BW, Dahlin DC. Giant-cell tumor of the sphenoid bone. Review of 10 cases. J Neurosurg 1983;59(2):322-327

3 Isaacson B, Berryhill W, Arts HA. Giant-cell tumors of the temporal bone: management strategies. Skull Base 2009;19(4):291-301
4 Morriss-Kay GM. Derivation of the mammalian skull vault. J Anat 2001;199(Pt 1-2):143-151

5 Wülling M, Engels C, Jesse N, Werner M, Delling G, Kaiser E. The nature of giant cell tumor of bone. J Cancer Res Clin Oncol 2001; 127(8):467-474

6 Harris AE, Beckner ME, Barnes L, Kassam A, Horowitz M. Giant cell tumor of the skull: a case report and review of the literature. Surg Neurol 2004;61(3):274-277

7 Sanerkin NG. Malignancy, aggressiveness, and recurrence in giant cell tumor of bone. Cancer 1980;46(7):1641-1649

8 Brien EW, Mirra JM, Kessler S, Suen M, Ho JK, Yang WT. Benign giant cell tumor of bone with osteosarcomatous transformation ("dedifferentiated" primary malignant GCT): report of two cases. Skeletal Radiol 1997;26(4):246-255

9 Dahlin DC. Caldwell Lecture. Giant cell tumor of bone: highlights of 407 cases. AJR Am J Roentgenol 1985;144(5):955-960

10 Lee HJ, Lum C. Giant-cell tumor of the skull base. Neuroradiology 1999;41(4):305-307

11 Ueda Y, Imai K, Tsuchiya H, et al. Matrix metalloproteinase 9 (gelatinase B) is expressed in multinucleated giant cells of human giant cell tumor of bone and is associated with vascular invasion. Am J Pathol 1996;148(2):611-622

12 Findlay JM, Chiasson D, Hudson AR, Chui M. Giant-cell tumor of the middle cranial fossa. Case report. J Neurosurg 1987;66(6): 924-928

13 Ohaegbulam SC, Gupta IM. Giant cell tumour of the sphenoid bone with dural extension. J Neurol Neurosurg Psychiatry 1977;40(8): 790-794

14 Goldenberg RR, Campbell CJ, Bonfiglio M. Giant-cell tumor of bone. An analysis of two hundred and eighteen cases. J Bone Joint Surg Am 1970;52(4):619-664

15 Dahlin DC, Cupps RE, Johnson EW Jr. Giant-cell tumor: a study of 195 cases. Cancer 1970;25(5):1061-1070

16 Seider MJ, Rich TA, Ayala AG, Murray JA. Giant cell tumors of bone: treatment with radiation therapy. Radiology 1986;161(2): 537-540

17 Malone S, O'Sullivan B, Catton C, Bell R, Fornasier V, Davis A. Longterm follow-up of efficacy and safety of megavoltage radiotherapy in high-risk giant cell tumors of bone. Int J Radiat Oncol Biol Phys 1995;33(3):689-694

18 Glasscock ME III, Hunt WE. Giant-cell tumor of the sphenoid and temporal bones. Laryngoscope 1974;84(7):1181-1187 